\title{
Enacting Motherhood Online: How Facebook and Mommy Blogs Reinforce White Ideologies of the New Momism
}

\author{
Charity L. Gibson ${ }^{1 *}$
}

Published: September 10, 2019

\begin{abstract}
Mommy blogs and social media platform Facebook are two ways that 21st century mothers today share their experiences digitally via the 'momosphere'. However, this is often another form in which white femininity is reproduced in popular culture. (Socially privileged white women have the most monetary resources, leisure time, education, and jobs encouraging or requiring the use of technology, resulting in their being the most technology fluent.) In many ways, such writings continue the trend of 'intensive mothering', which is Sharon Hays' widely adopted term for a woman whose identity revolves around her children. It is also similar to what Susan Douglas and Meredith Michaels call the 'new momism'. White notions of motherguilt and fear of mother-blame are countered by attempts to perform the good mother role online and seek validation. Especially mothers lacking in a meaningful community of friends or family gravitate toward this artificial online community. While progress has begun in mothers feeling validated to share their private maternal lives in public realms, there is still work to be done regarding how women feel they can and cannot represent their maternal selves. Unless mothers learn to deconstruct mainstream ideologies of motherhood, they will continue to uphold them in their online personas.
\end{abstract}

Keywords: momosphere, Facebook, mommy blogs, new momism

\section{INTRODUCTION}

Many $21^{\text {st }}$ century mothers seek to publicise their maternal identity online, often popularly referenced as the 'momosphere'. Mommy blogs and social media platforms such as Facebook are at least two digital outlets through which women today seek to share their experiences. However, while emphasis on celebrating (and at times lamenting) maternity can be positive, especially as social media gives voice to mothers who may not consider themselves writers, it may also be another form of white femininity reproducing itself in popular culture, as socially sanctioned online personas of motherhood tend to follow white cultural norms. Because cultural standards linked to whiteness are regarded as universal, commentary on Western motherhood is often accepted as relevant to all women rather than something that mostly impacts white women specifically (Nakayama and Krizek, 1995). Recognising dominant ideologies as influenced by whiteness allows situations in which women of colour can be lauded for ways they have resisted embodying reductive and racist portrayals of motherhood and instead models of white motherhood can be constructed as aspirational for them.

Sadie Plant coined the term cyberfeminism in 1994 'to describe the work of feminists interested in theorizing, critiquing, and exploiting the Internet, cyberspace, and new-media technologies in general' (Consalvo, 2002: 109). However, the integration of online motherhood with the social constructedness of 'race' ${ }^{1}$ has been and continues to be little explored territory. In 2009, Jessie Daniels acknowledged that 'it is exceedingly rare within both cyberfeminist practices and critiques of them to see any reference to the intersection of gender and race'; while some headway has occurred, regarding a specific focus on online motherhood and race, today there remains much work to do (Daniels, 2009: 103).

${ }^{1} \mathrm{I}$ am distinguishing race from ethnicity in the sense that race is not only one's cultural background and physical distinctions but also the way in which one has constructed his or her identity considering cultural responses and stigmas. I am using race to identify a social group that has formed in light of society's treatment of ethnicity. 
As I am applying a critical whiteness lens, ${ }^{2}$ it is noteworthy that racial inequity persists online as much as anywhere else. Lisa Nakamura and Peter A. Chow-White acknowledge that 'no matter how 'digital' we become, the continuing problem of social inequality along racial lines persists...the digital is altering our understanding of what race is as well as nurturing new types of inequality along racial lines' (2011: 1-2). Because white women have more monetary resources, leisure time, education, and jobs encouraging or requiring the use of technology, it is unsurprising that most technology-fluent women are white and, although the divide is not as wide as it used to be, there continues to exist 'unequal access to digital media technologies across racial and ethnic lines'. (Nakamura and Chow-White, 2011: 5)

In USA culture, more white women than women of colour write about motherhood via motherhood memoirs, a genre rooted in print culture in which women write of their identities as mothers. Furthermore, I believe that a similar trend occurs online as white women are most likely to be in a privileged position with access to online resources. Motherhood memoirs, in which women narrow their roles primarily to that of a caregiver, have largely adhered to the practise of 'intensive mothering', which is Sharon Hays' (1998) widely adopted term for a woman's identity, centring on her role as an ever-nurturing and unselfish mother. Hay's concept is similar to what Susan J. Douglas and Meredith W. Michaels call the 'new momism' (2005), in which both subtly and blatantly, the values reinforce conventional expectations of how mothers should act. Douglas and Michaels' work, rather than becoming dated, is seminal in the field, as relevant now as ever. Lynn O'Brien Hallstein speaks of Douglas and Michaels' impact, saying that 'the new momism has become an object of study among feminists and motherhood scholars, and these scholars are detailing the various ways that the new momism continues to shape contemporary motherhood' (2014: 188). The tenets of maternal ideologies exemplified via motherhood memoir are moving to new online forms. It is also necessary to recognise a racial component at work regarding the ideology of this new momism, as the idea of a good mother who dedicates her life solely to motherhood is predominantly a white mandated expectation. Douglas and Michaels point out that Western culture's portrayal of and adherence to the new momism 'serves to divide us by age and race and 'lifestyle choices" and that 'the white, upper-middle-class, married-with-children nuclear family remains...dominant' (Douglas and Michaels, 2005: 22). Ironically, Douglas and Michaels' desire for unity amongst mothers of all colours creates a division in which mothers of colour are assumed to function as de facto white mothers because whiteness fails to be addressed as an inherent norm within dominant culture. Sarah J. Schoppe-Sullivan is one of the few scholars who attends to this, saying that intensive mothering is particularly prominent in middle- and upper-class White women' (Schoppe-Sullivan, 2016: 278). Thus, although high expectations of motherhood impact all women in some ways, white culture has been especially privy to aspiring to meet these benchmarks. Evelyn Nakano Glenn writes, "What may be needed to emphasize the social base of mothering is attending to the variation rather than searching for the universal" (Glenn, 1983: 5). Thus, although it is first useful to note trends within white expectations of motherhood, from there is it also necessary to consider how groups formed outside the dominant culture may vary in their practices and expectations and become excluded in representational norms.

Expectations of motherhood are firmly embedded in print media. Influential motherhood theorist Andrea O'Reilly has recognised the subsuming influence of maternal expectation, saying, "Most motherhood memoirs, because of their identification with the new momism, cannot discern, let alone critique, the root causes of mother's oppression" (2011: 212). Moving beyond O'Reilly's feminist claim, we must also recognise that racial dimensions impact all chronicles of motherhood and the same conservative and normative underpinnings which have driven print maternal writings also may be at work in the digital world. Unfortunately, very few studies have focused on race directly in analysing the ways that mothers express themselves online. Scholars must recognise that analysing mothers' online performance without considering how white culture might reinforce itself online, can result in a kind of colour-blindness. However, it is difficult to analyse how performances of online motherhood intersect with race because this aspect of one's identity is not always apparent. May Friedman notes that 'people can construct online identities that do not reveal physical characteristics... the absence of the body tends to erase marginalized identities that are not specifically referenced' (2013: 19). Therefore, while studies of possible differences in how white mothers and mothers of colour enact their motherhood online is important and suggestive of underlying ideologies, the necessary data, because of the nature of the technological interface, is difficult to obtain.

In conducting my research, I largely relied on published case studies and analyzed these findings from a feminist and critical whiteness lens. However, I then applied my interpretation of the data to my own perusals of Facebook pages and blog sites and found my hypothesis confirmed. I surveyed the Facebook pages of those already within my friend network, thus many of them I have been observing for years. I surveyed around twenty-five blogs, none

\footnotetext{
${ }^{2}$ Critical whiteness theory analyzes how whiteness is constructed (individually as well as socially) and the related moral repercussions. It not only calls attention to blatant and subtle racism but it also calls attention to the nuances of internalized and unquestioned, perhaps even unconscious, acceptance of white superiority. Ruth Frankenberg (1997) states, "For the most part, critical work on whiteness has emerged in the context of, and very frequently in direct response to, critique of racism and the racial order focused on positions of subordination, whether the latter is undertaken by people of color (as has most often been the case) or by white people" (2).
} 
of whose authors I personally knew, and chose them based on their title, which I found through using search terms such as "mommy blogs" and "blogs about motherhood." I surveyed the blogs over a months' time span but was able to view archived posts spanning up to years past. I sought to respect the privacy of those whose pages I visited by never referencing anyone from Facebook by name and never using actual content from anyone's pages or posts. Regarding the blogs, I did use some titles and author names, since this information is made public, but I overall sought to look for patterns amongst the blogs rather than fixating on any individual blog or author.

When analysing motherhood accounts posted on the internet, it is useful to shift from the term 'memoir' to 'narrative' because memoir, like autobiography, suggests a work that is complete and which chronicles reflexive, selective experiences from which the author has had at least some degree of temporal distance. In contrast, because of the internet's immediacy, mothers who write online share their stories while in the midst of experiencing them. There is often little lag time, either from when the event occurs to the time it is written about and shared or from the time it is written to the time the mother begins receiving feedback. As opposed to a cohesive published narrative, which is a literary reworking, the online narratives are snippets; in the case of Facebook, they are often phrases or sentences; in the case of blogs, they are vignettes, capable of standing alone but also still existing in iteration.

Some may argue the heyday of Facebook is over, as adolescents and young adults are moving to other online sites ('Teens are Abandoning Facebook', 2018). While this is true for teens, I have chosen to analyse Facebook because it remains a dominant outlet for mothers at the time of writing. Maeve Duggan et al state in Pew Research Center's report that $81 \%$ of mothers used Facebook (2015: 1). This number has remained mostly consistent, as Edison's Research 'Moms and Media 2017' report states that 84\% of mothers used Facebook. A potential reason for such a strong maternal presence on Facebook may be that mothers are more likely to stay home or be home during non-working hours and may check Facebook to break up housework and daily routines. Also, mothers tend to engage in activities targeted toward the children, such as soccer practice, playground time, and so on in which the mother may multitask and be on social media platforms at the same time. Bridget Genell Therriault has analysed Facebook's intersection with motherhood. Therriault addresses how mothers relate to a collective group online: "[M]others engaging in Mommy Facebooking validate their individual motherhood identities while also perpetuating society's idealization of the good mother through social engagement and interaction with audiences on Facebook" (Therriault, 2014: 3). According to Therriault's study, mothers use Facebook because it is a contemporary way to enact and display intensive mothering, which continues to be according to socially mandated beliefs of the 'good mother'. Therriault conducted her research on real mothers' posts on Facebook and found three main themes that emerged:

Promotion of children's activities/milestones, mothers discussing acts of nurturing, and mothers sharing thoughts on the sacrifices and rewards of motherhood represent sentiments that are widely associated with characteristics of the ideal mother, and as such, these were the attributes used by mothers in their online motherhood performances. Conversely, there was rarely any Facebook commenting that discussed feeling of ambivalence related to motherhood. (Therriault, 2014: 53)

While O'Reilly has pointed out that motherhood memoirs identify problems with the cultural expectations of mothers but offers no solutions or challenges, Facebook maternal narratives do not seem to be even be pointing out the problems (O'Reilly, 2011: 212). Part of the reason may be that print memoirs tend to be written by academics or professional writers who are used to being self-reflexive and deconstructing dominant contemporary ideologies. Facebook, by contrast, is an amateur, open portal for ordinary people to express themselves and perform their identity. This is not to say that mothers on Facebook never write negative things about their parenting. For example, a mother may post something along the lines of 'health food fail' next to a picture of her children licking ice cream cones. Yet, even amidst her self-deprecation of food choices, there tends to be an underlying message reinforcing intensive mothering, that it is to say a performative act seeking to reinforce that the mother loves her children deeply, including giving them rewards (good mothers make good children). Typical comments or responses reaffirm the mother, either by focusing on the important memories being made or admitting to one's own equally unhealthy choices. Community feedback plays a large role, and acceptance from the group is important as the mother makes decisions about what to share on Facebook. Therriault reports that in her study, any potentially controversial posts about motherhood received little response in comparison with posts that re-represented social norms (Therriault, 2014: 52). This seems to indicate that audiences of mothers, or those interested in topics related to mothering, do not want to engage in division but instead seek agreement, reinforcement of norms, and hence, community.

There is a body of research focused on asserting how social media sites provide social support to parents. Some analyse Facebook specifically, maintaining that the site allows for the creation and reinforcement of maternal community (see for example M. Bartholomew, et al. (2012); E. M Thoren et al. (2015); and B. Holtz, et al. (2015). Yet, in the midst of mothers seeking community is the need for differentiation. Facebook mommies appear to 
desire relationship with others and to show ways in which they as parents and their children are, if not superior, at least pretty special. Tracey Harrington McCoy reports that the competitive parenting spirit on Facebook can hurt a mother's sense of self: "For the mom who barely gets her kids' shoes on before hustling them off to school, posts that portray the perfect family can churn up guilt or even self-loathing" (McCoy, 2013). Of course, Facebook is not a true community in the sense of people who know each other and belong to one another. Research shows that the typical parent on Facebook has 150 friends but that only one third of them are 'actual' friends' (Duggan, 2015: 1). McCoy notes that social media actually can be a place lacking in social graces when intimate relationships do not support the interactions: "It's unlikely a mom will shame a good friend in public for having different values or beliefs, but when the person is just an acquaintance, the rules change" (McCoy, 2013). The irony is that mothers seek social acceptance on Facebook from people who do not truly know them. Communities are defined as groups sharing beliefs and values related to actions and conduct, but 'on Facebook... there's no filter, no rules, no precedent' (McCoy, 2013). Chances for rudeness, trolling, and even shaming increase when mothers who have no relationship offline interact with one another in a realm void of social cues such as facial expression, tone of voice, and body language which typically assist in communication. Unlike in Real Life, on the Internet, friends are made and lost by the click of a mouse.

Therriault and McCoy argue that adhering to the script of maternal perfection online via Facebook can lead to feelings of isolation, which foster a subconscious spirit of competition amongst women; however, neither of them directly consider race. Based on the patterns of intensive mothering emerging from their research, it appears that most, if not all, of the profiles examined were those of white women and we might speculate that those profiles were strongly influenced by cultural expectations of whiteness. Stephanie Hartzell traces the history of expectations and enactments of maternal perfection, "[n]ormative constructions of 'good motherhood' have historically been articulated with a white, middle-class (heterosexual) formation... only white middle-class mothers are able to perform the type of nurturing articulated to 'good motherhood"' (Hartzell, 2017: 65). Such enactments of good motherhood continue on Facebook when women accustomed to performing intensive mothering or the new momism continue this pattern of assumption online. Although it is difficult to obtain information on ethnicity, since this is not a category users are asked to identify, Cameron Marlow's article 'How Diverse is Facebook?' gives an in-depth analysis of ways in which the information was obtained and reports, "We have found that while Facebook has always been diverse, this diversity has increased over time leading to a population that today looks very similar to the U.S. population" (Marlow, 2009). However, while as ethnic minorities appear to be as (un)equally represented on Facebook as they are elsewhere (meaning that the majority of users are white), it is unclear whether minority mothers use Facebook habitually, as much as white mothers do. One recent study on new mothers found that using Facebook leads to feelings of depression, from a participant pool comprised $86 \%$ of white women (Schoppe-Sullivan, 2016: 286). The study confirms that societally influenced mothers 'who were more concerned with external validation of their identities as mothers and those who believed that society holds them to excessively high standards for parenting' are most likely to be negatively impacted emotionally and psychologically. As the study mostly analyses white women's Facebook activity, this may suggest an adherence to white presumptive norms (Schoppe-Sullivan, 2016: 276), as stated earlier, "[Intensive mothering is particularly prominent in middle- and upper-class White women" (Schoppe-Sullivan, 2016: 278).

While hard and fast data on the ethnic and racial background of mothers using Facebook is difficult to obtain, I would like to suggest that women of colour appear reticent to conform to white motherhood mandates. Women of colour do not seem to be drawn to print memoirs in the same way that white women apparently do, perhaps because they do not feel the need to enact a perfect, and possibly competitive, mother image. The exception could be the current marketability of 'Tiger Moms', which may have much to do with the publishing industries stereotyping of Asian over-achievement (and selling that model to white audiences). I speculate that mothers of colour largely do not read themselves solely through the lens of their maternity or see their enterprise as mothers as something so individualised that they want to write solely about their 'exceptional' experiences. Deeshaw Philyaw suggests that black women specifically and women of colour in general simply feel less ambivalence toward motherhood. However, she also argues that even the motherhood memoirs that are written by minority women do not receive the same level as attention as the white ones, and of course, many more may never be accepted for publication. Due to such experiences of minority women being overlooked, 'women of color don't see their mothering experiences and concerns reflected in the mommy media machine', and so '[a]ffluent white women are the only mothers who really matter' (Philyaw, 2016). While scholars like Philyaw are specifically writing about print culture, I suggest we can draw parallels with the online performances of motherhood too.

While little research on people of colour's online communities exist, there has been ample research conducted regarding physical communities of colour. Research from a critical race perspective mostly compares strong fictive kin ties (non- biologically related friends) in cultures of colour with the weak fictive kinship ties in white culture. Helen Rose Ebaugh and Mary Curry report that 'most research on friendship networks among Anglos fails to document any type of fictive kin relation', suggesting that most white friendships do not foster the type of intimacy 
typical in familial relations (Ebaugh and Curry, 2000: 193). I have not been able to find any relevant, updated studies that have occurred since Ebaugh and Curry's research, suggesting a worrying lack of scholarly interest in racial differences regarding women's friendships. Exposing why white culture has little expectations of friends and family regarding supportive community requires a retrieval of part of the core American mythos. Soong-Chan Rah claims, "Western, white culture, has placed at the center of its theology and ecclesiology the primacy of the individual" (2009: 29). Stephanie M. Walls argues something similar, "On the individual level, modern individualism negatively affects the quality of life for each person through promoting alienation" (2015: 146). This alienation is self-imposed but enacted due to an individual's desire, likely unconscious, to adhere to dominant standards of interaction. Facebook mothers' attempts to build online communities may possibly stem from a lack in these women's own tangible networks, be it due to distance, schedules, or strained family and friend dynamics.

Minority cultures, or rather black culture specifically, have a very different history to that of white competitive isolationism. In her seminal and groundbreaking work, Patricia Hill Collins explains some of the historical communal practices enacted by women in black culture,

[T] he boundaries distinguishing biological mothers of children from the other women who care for children are often fluid and changing...vesting one person with full responsibility for mothering a child may not be wise or possible. (Collins, 1991: 46)

This acceptance of responsibility and concern that black women take for one another's children helps reduce a mother's fear of failure and inadequacy because she is not exclusively responsible for providing for and guiding her children. This model is in direct contrast to the white practices surrounding motherhood, which is the belief 'that mothering occurs within the confines of a private, nuclear family household where the mother has almost total responsibility for child-rearing' (Collins, 1991: 43). While the term othermothering was originally specific to African American culture, many minority cultures enact some form of similar practices, of a more collective form of parenting. Research proves that minority cultures, including Chicana and Asian American, typically include communities of kin in which family members from different generations interact in providing familial assistance in childrearing (Greenman 2011; Segura and Pierce 1993).

Facebook mothers' motivation to enact their mothering persona online, perhaps subconsciously seeking some form of validation of or recognition for their efforts, may stem from the likelihood that these women are white and, therefore, statistically speaking, less likely to be involved in regularly interacting communities which support one another in meaningful ways. According to Duggan, ' $45 \%$ of mothers who use social media 'strongly agree' that they get support from friends on social media' (2015: 1). The results are based on a 56\% white demographic pool (Duggan, 2015: 8.) Thus, I wonder about these white women's interpretation of the word 'support' and even the word 'friend', especially when this survey is contrasted with research about Facebook mothers (86\% white) suffering from depression due to the societal expectations enacted online (Schoppe-Sullivan, 2016: 286). Sherry Turkle notoriously argued that only faux support exists online,

If we start to call online spaces where we are with other people 'communities,' it is easy to forget what that word used to mean...Communities are constituted by physical proximity, shared concerns, real consequences, and common responsibilities. Its members help each other in the most practical ways... What do we owe to each other in simulation? (Turkle, 2011: 239)

Perhaps social media outlets like Facebook are allowing white women feelings of 'being heard' online, without meeting the actual tenets (and demands) of true off-line community.

In shifting from Facebook to the blogosphere, 'mommy blogging' has been a key term to describe the thousands of mothers who write about their experience of motherhood through frequent (that is to say at least once a month) blog postings. Altogether, more Facebook mothers post, however, the numbers still add up for blogging, as Deborah Whitehead states that 'more than half of all active female internet users participate in some form of blog activity weekly, publishing, posting, or reading' (Whitehead, 2014: 127). According to eMarketer, "Nearly four in 10 online moms read blogs at least once per month in 2012, and more than 4 million moms wrote them" "Moms Still Make Social a Priority", 2013). Thus, despite mommy blogs not being the norm for every household, they are still a force to be reckoned with, evident from the fact that most are at least familiar with the phrase 'mommy blogger'.

One of the primary ways that mommy blogging differs from Mommy Facebooking is that bloggers tend to have a more prominent literary voice, whereas on Facebook, mothers typically post short amounts of text (often accompanied by pictures) and largely rely on the voices of others to state their beliefs by reposting, as many simply post articles by others with whom they agree, rather than by writing original material themselves. However, mommy blogs are similar to Facebook posts in that they both receive comments and feedback from peer readers. For this reason, Friedman insists that 'mommyblogging...departs completely from individual notions of 
subjectivity with the presumption of a stable individual author. Instead, mommybloggers are collectively creating a dynamic cyberorganism that is endlessly evolving' (Friedman, 2013: 142). The digital technology of the Internet changes motherhood memoiring, be it via Facebook or blogs, into something that is more interactional, reactional, and iterative. However, despite this similarity, the monetary status of mothers using these sites may vary. There may be more socioeconomic disparity on Facebook, whereas " $[\mathrm{t}]$ he average mommy blog's household income $\mathrm{i}[\mathrm{s}]$ $\$ 84,000$ [which is] $\$ 14,000$ higher than average income for non-blogging moms. Moms who read or contribute to blogs are also $52 \%$ more likely to have college degrees than moms who don't, according to Scarborough" (Laird, 2012). Thus, these mommy blogs are written by women who benefit from middle class privilege, demographically more likely to be white women.

The current studies on mommy blogs tend to focus on themes such as female identity and community, with less information available regarding race (see for example D. DiPrince (2012); E. Petersen (2015); and J. Abetz and Moore, J. (2018). As Jen Schradie notes, "The scholarship on the relationship between class and race or ethnicity is underdeveloped in digital production" (2012: 557). Though Schradie does not focus on mothers who blog, her study does have interesting findings regarding race, "Although Black Americans are less likely to be online than White Americans, among those online, Blacks are more likely to blog than Whites. Meanwhile, Hispanics are equally likely to blog than non-Hispanics (Schradie, 2012: 561). Schradie speculates that black bloggers may be seeking a form of community online that emphasises "shared identity and cultural expression" (2012: 567). There is no firm data for how many women of colour blog on maternal related issues. In fact, Babble.com's list of the top 100 'mom blogs' of 2011 only included seven blogs from women of colour (qtd. in HuffPost, 2012). Bitch Media's article entitled "Mothers of Intention: Five Bloggers on Race and Erasure in the Mommy Blogosphere" includes five interviewed mothers who provide some useful insight. Arwyn Daemyir, who writes the blog Raising My Boychick, poses the question of whether women of colour are actually absent from mommy blogs or simply overlooked: 'The media constructs 'mom blogs' as white, middle class, capitalistic — so those of us who aren't don't identify as such, and thus are nowhere to be found when journalists go looking for 'mom blogs,' thus perpetuating the whitewashing" ('Mothers of Intention', 2011). Shay Stewart-Bouley, who writes the blog Black Girl in Maine, suggests that part of the reason women of colour are not typically labelled as mommy bloggers has to do with their being less likely to separate motherhood from the rest of their life, or to only discuss their parenting status:

$[\mathrm{O}]$ riginally I thought [my blog] might be a mommy blog, but it became quickly apparent that it really was not. As a black woman in America, even when I tried to focus strictly on parenting, the reality is my work had a certain level of intersectionality involved. Race and class are an integral part of my identity, something that is rarely discussed in most so-called mommy blogs. ('Mothers of Intention', 2011)

Scholars may be overlooking mommy blogs of women of colour for this reason. They may also be deemed too 'political' for the genre. Stewart-Bouley hypothesises over the reason women of colour are so overlooked within the mommy blog genre: "I think it's hard for others to think outside the box and realize non-white bloggers can be active in discussions aside from race" ('Mothers of Intention', 2011). For non-white bloggers then, motherhood is implicated in racial and class politics in a way in which the privilege of whiteness can ignore.

One of the central debates about mommy blogs is whether these mother writers adhere to myths of motherhood or challenge them. Gina Mascullo Chen argues that the term itself 'reinforces women's hegemonic normative roles as nurturers, thrusting women who blog about their children into a form of digital domesticity in the blogosphere' (2013: 510). However, others such as Marshiela M. Banner (2016) argue that mommy blogging is a radical act. When motherhood is authentically portrayed and bloggers show the difficulty of obtaining maternal perfection, patriarchal expectations can be challenged. " $[\mathrm{P}]$ ersonal blogs about mothering promise an unedited, entertaining picture of motherhood as it exists in real life, not on TV or in glossy magazines...the successful mom blogger promises real revelation and unvarnished truth" (Whitehead, 2014: 129). In my perusal of mommy blogs, it became evident through blog titles such as Her Bad Mother, Mama's Losin' It, The Good Enuf Mommy, I'm NOT Super Mom, and The Anti-June Cleaver that some authors do resist the idea of maternal perfection. However, equally noteworthy is that these women, much like Facebook mothers, still predominantly adhere to the new momism or intensive mothering beliefs that parenting is primarily the mother's responsibility and that their life should revolve around their children.

Fourteen years ago Douglas and Meredith analysed how 'the motherhood Web reflects the cultural tensions that fuel the new momism' through 'an obsessive fixation on the details of child rearing and domestic life' (2005: 313) and the same can be said for many mommy blogs today. For every blog title suggesting a resistance to maternal perfection, there are others seemingly reifying this concept. In analysing blog themes they do seem to fall within Douglas and Meredith's key topics, such as health, consumerism, homeschooling, stay-at-home mothering: health mommy blogs include 100 Days of Real Food, Healtby Happy Thrifty Family, Wellness Mama, Up Run for Life, Organic Parenthood, and Healing Mama Remedies. Stay at home mom blogs include 24/ 7 MOMS, The Stay at Home Life, Home 
with Aneta, Stay at Home Mom of One, and My SAHM Life. Blogs focused on consumerism and shopping include Thrifty Nifty Mom, Shop with me Mama, Mommies with Cents, The Shopping Mama, and Mom Style Lab. Blogs that in their title adhere to an idolisation of maternity include The Good Mama, All About the Child, Happy Mum Happy Child, Happy and Humble, Mommy Knows What's Best, and Successful Mommy Advice. Such patterns in the blogging momosphere adhere to the same ideologically burdensome views on motherhood that white women held before they started speaking for themselves online. Although there is a misconception that when women speak for themselves, as opposed to being written about, they will break away from oppressive ideologies of motherhood, mommy blogs show that such is not the case, largely because women are not even aware of the extent to what they are succumbing to dominant expectations. Lopez accurately identifies how,

As yet, mommy bloggers have not come together to tackle social justice or political issues such as parental leave, the cost of daycare and healthcare, workplace equity or any other issue that might benefit from their grass roots mobilization and community organizing. (Lopez, 2009: 740)

Thus, my survey concluded that mommy blogs mostly showcase domestic issues of motherhood rather than political ones.

Some may argue that mommy blogs are still positive because they provide much needed community for women, and that the community may change and evolve over time due to the ongoing and supportive interactions with fellow women. Aimee Morrison argues that 'personal mommy blogs are best understood as motivated by a widespread need expressed by blogging mothers to create communities' (Morrison, 2010). Digital feedback is more specific, fragmented, and immediate. Morrison writes, "The reciprocity of the genre consists in the balance among its participants, the implicit agreement that if you read my blog and leave a comment, I should read your blog and support you there as well" (Morrison, 2010). The question then becomes what type of mothers are most likely to need the validation and support of an online community. Likely, it may be those lacking such community in 'real life.' Middle class white women are the ethnic group least likely to regularly participate in truly supportive community. Morrison acknowledges maternal isolation in modern America, saying that:

the public understanding of motherhood as an activity undertaken in the privacy of the nuclear family, and the widespread distribution of nuclear families into geographically disparate suburban communities removed from public amenities mean that mothers of young children are physically isolated from their existing social networks and contexts. (Morrison, 2010)

However, Morrison does not sufficiently consider racial implications; mothers of colour are much more likely to be engaged in non-virtual social networks, both with fictive and non-fictive kin. Therefore, Morrison's conclusion that mothers find replacement communities for those that are lacking through mommy blogging may be one example of 'whitewashing', though extended research must be conducted to confirm this hypothesis.

In this article, I would like to question whether mommy blogs provide true community for women, white or otherwise. It is evident that mothers participating in mommy blogs share many core beliefs and goals about motherhood, which does grant them the title of a virtual community. Lynne M. Webb and Brittney S. Lee make similar claims to Morrison's, in both normalising maternal isolation and viewing blogs as the solution: "Because modern U.S. life has depleted 'natural' community opportunities, community now requires coordination. Enter blogs" (Webb and Lee, 2011: 249). They then conclude that, "Because mommy bloggers read and comment upon each other's posts, they are positioned to provide and receive social support. By social support, we mean providing assistance and positive affirmation in times of need" (Webb and Lee, 2011: 250). Also similar to Morrison, Webb and Lee argue that because blogs foster reciprocity between writer and reader, they establish meaningful community.

Yet, can someone's posts and well-wishes regarding child-rearing and parental dilemmas replace the physicality of someone coming over to help? Can an online smiley face replace the warmth of an embrace for a stressed mother? People are most comforted and impacted by face to face interaction. Amy Banks and Leigh Ann Hirschman explain the importance of human contact and how a nerve called the smart vagus positively responds to uplifting face to face communication, saying that 'you get input from other people's faces and voices telling you that these people are safe... The smart vagus is one reason we're less stressed when we're around people we trust' (2016: 34). Thus, giving practical assistance with one's parenting is more helpful than simply giving advice on parenting, and the human embodiment occurring through such exchanges nourishes a weary parent's needs. While many argue that what is important is having a sounding board, regardless of whether a screen facilitates the exchange, Wilma A. Bainbridge et al's research leads them to advocate that "social psychologists should consider physical presence as a factor influencing trust, respect, and perhaps other aspects of social interaction" in a way that the virtual world does not offer (2011: 11), perhaps because digital fora so often function as echo chambers rather than providing the conditions for social engagement. 
Validations of life stage-based groups assume that community is most effective when shared with those going through similar experiences; yet, there is benefit too in engaging with those who are distanced from the situation and can provide a bird's eye view. Anna Kudak endorses multigenerational female relationships, saying, "Bridging the generation gap not only increases the friend pool, but it also expands and supports mental wellbeing...Friendships with older and younger people help broaden your perspective" (qtd. in Funderburg, 2012). Mommy blogs' tendency to limit their virtual community to those with the same current experiences and basic demography, minimally develops community compared to many minority cultures' embracement of a diverse support group for mothers. If white mothers are distanced from their family or do not have a meaningful, diverse community, as can often be found, for example, through religious affiliation ${ }^{3}$, then perhaps they are more likely to seek to participate in a purposefully constructed community of likeminded mothers online.

My hypothesis is that it is mostly white mothers who are blogging as a way to find community. This is not to say that women of colour who are mothers are not blogging; however, their sites do not appear to fall into the same narrow topical content as many mommy blogs, perhaps because the content is less domestic and the motivation necessarily less about building community. For example, Marquaysa Battle claims in her article '8 Black Mommy Bloggers To Follow Now',

Long gone are the days when a woman's identity as a mother overshadows everything else in her life...motherhood may sit at the top of the list, but isn't the entire list. There are also bloggers who provide a lot of practical inspiration with tips for moms about keeping a full life even while taking on the important role that is raising a child. (2017)

Contrastingly, while many white mommy bloggers resist the idea of maternal perfection, they still seem to cling to motherhood as the central defining aspect of their persona. Friedman, who self-identifies as a brown woman, claims that she has found many 'non-normative mothers and parenting practices' through mommy blogs (2013: 5). She claims that the mommy bloggers she has read 'self-identify across the spectrum of race, including many mothers with hybridized racial identities' (2013: 50). I find Friedman's claim encouraging; however, Friedman is an academic and self-proclaimed feminist which may prompt her more than the average woman to have the research skills to find subversive blogs challenging norms of motherhood. However in my online research, no-one else has echoed Friedman's assertion in the past six years since she made it. Facebook posting remains more popular than mommy-blogs. Sarah Pulliam Bailey suggests, "The death of the mom blog has something to do with shifts in how people consume and create on the Internet" (2018). Elizabeth Tenety claims that other platforms have taken over because mommy blogs' 'core audience is trending towards hanging out on their phones - and by extension social media sites like Instagram and Facebook - the digital environment overall is less of a fit for those types of blogs' (qtd. in Bailey 2018). Thus, perhaps it is important to recognise that when mommy blogs, according to Friedman, were on the verge of being diversified, they somewhat decreased to be replaced by instantaneous social media sites like Instagram and Facebook where mothers remain somewhat in thrall to the representational cult of maternal expectation. Researchers need to historicise the peak years of the mommy blog (approximately 2005-2015), recognising that while mothers still blog in 2019, it may no longer be the phenomenon it once was.

In conclusion, mothers who enact their identity online appear to seek validation. Especially mothers who are distanced from family or have apparently not fostered a meaningful community of friends gravitate toward this online community, for example, one mother says,

[1]n my early days of parenting a newborn, I credit some 'mom blogs' with being my online life raft. I felt really lost and unsure of myself and the parenting community I discovered online helped me stay sane and find support in such a challenging and sometimes scary time, and for that I will be forever grateful. ('Blogs around the Momosphere', 2012)

Using the internet as a resource can be an effective way to allow parents to see themselves as capable with peer appraisal, rather than having to rely wholly on professionals. Lars Plantin and Kristian Daneback explain, "An important reason to the increasing number of parents who turn to the internet for information and interaction has shown to be the weakened support many of today's parents experience from their own parents, relatives and friends" (2009: 1). This research suggests that parents turn to online support and assistance because they have a void in their own lives regarding meaningful parental assistance. Thus, although I do not perceive it as feasible or even helpful to advocate mothers abandoning their online interactions, it is important to recognise that online groups are not synonymous with tangible support from friends and family.

Whilst physical community may be more authentic and helpful than virtual communities, mothering young children requires spending large amounts of time at home, which can be isolating. Working while parenting leaves

\footnotetext{
3 Walls posits, "Historically, religion had been a path toward community building, community obligation, and cooperation among individuals" (2015: 103). Gibson explains, “As we bond with God, we bond with other 'kin' who share our beliefs.” (2005: 14).
} 
little room for socialisation, and many women relocate to a new place where they know few people when they become heterosexually partnered and start a family. It is no wonder that mothers gravitate to online communities when so many factors complicate the possibility of physical ones. Online community may be alright in moderation and with caveats, and, in fact, some online groups exist to connect people in their 'real lives', helping mothers coordinate times to meet in person, informing them of events where engagement can occur, and helping keep women connected until they see each other again. However, many groups exist where the participants will rarely or never meet. It is likely these groups, almost exclusively representational rather than real, where emphasis on performing the good mother role comes out most strongly. Celebrity mother Joanna Gaines acknowledges how media creates inauthenticity. Going from being unknown to having an Instagram following, she admits,

I could feel insecurity start to creep in...I found myself critiquing if there were messy backgrounds or blurry smiles...It is so easy to let social media rob us of authentic moments... We make adjustmentsfind better lighting, dress our kids in something nicer. (2019: 56-7)

Gaines' recognition of the internet's glorification of perfection, including maternal competency, is insightful. Her own ethnic background (being $1 / 4$ Lebanese and $1 / 2$ Korean) may assist her in resisting distantiating cultural mandates.

Society is so critical of mothers that it is perhaps inevitable for us to desire to make a good impression on our virtual peers. However, in my own experience as a white mother myself, though I still struggle at times, I have found several effective techniques in resisting intensive mothering dictates online. I have limited my public postings and post mainly in private groups and sites where I have actual relationships with women when I need advice or assistance. This helps free me from needing parental validation from others who are 'virtual strangers'. Motherhood is hard; dominant culture's expectations of motherhood, which typically reinforce white, middle class ideologies of maternal appropriateness, only make it harder. Women of colour who have resisted reductive scripts of mainstream culture's expectation of performative motherhood can teach much to feminist and critical whiteness studies. As Daniels notes, "[W] hen cyberfeminists explicitly engage both gender and race it is both conspicuous and instructive" (2009: 104). Such undertakings allow white mothers like myself to acknowledge the root of our motivations and to seek to surround ourselves with communities that are truly fulfilling, rather than simply reinforcing patriarchally-rooted obligations through semi-autonomous digital platforms.

\section{REFERENCES}

Abetz, J. and Moore, J. (2018). Welcome to the mommy Wars, ladies": Making sense of the ideology of combative mothering in mommy blogs. Communication, Culture and Critique, 11(2), 265-281. https://doi.org/10.1093/ccc/tcy008

Bailey, S. P. (2018). How the mom internet became a spotless, sponsored void. The Washington Post. Available at: https://www.washingtonpost.com/outlook/how-the-mom-internet-became-a-spotless-sponsored-void/2018 /01/26/072b46ac-01d6-11e8-bb03-722769454f82_story.html?utm_term=.bdf96a66b70a

Bainbridge, W. A., Hart, J.W., Kim, E. S. and Scassellati, B. (2011). The benefits of interactions with physically present robots over video-displayed agents. International Journal of Social Robotics, 3(1), 41-52. https://doi.org/10.1007/s12369-010-0082-7

Banks, A. and Hirschman, L. A. (2016). Wired to Connect: The Surprising Link between Brain Science and Strong, Healtby Relationships. New York: Penguin Random House.

Banner, M. (2016). The Radical Act of Mommy Blogging: Challenging Dominant Narratives of Motherhood Through Literal and Figurative Rhetoric. Boise State University, Master's Thesis.

Bartholomew, M. K., Schoppe-Sullivan, S. J., Glassman, M., Kamp Susch, C. M. and Sullivan, J. M. (2012). New parents' Facebook use at the transition to parenthood. Family Relations, 61(3), 455-469. https://doi.org/10.1111/j.1741-3729.2012.00708.x

Bitch Media (2011). Mothers of intention: Five bloggers on race and erasure in the mommy blogosphere (editorial), Bitch Media, 18 August 2011. Available at: http://bitchmedia.org/article/mothers-of-intention (Accessed 20 December 2018).

"Blogs around the momosphere, or the other way around..." (2012.) My SD Moms. Available at: http://mysdmoms.com/2012/11/blogs-around-the-momosphere-or-the-other-way-around (Accessed 28 November 2018).

Chen, G. M. (2013). Don't call me that: A techno-feminist critique of the term mommy blogger. Mass Communication and Society, 16(4), 510-532. https://doi.org/10.1080 /15205436.2012.737888. 
Collins, P. H. (1991). The meaning of motherhood in black culture and black mother-daughter relationships, in P. Bell-Scott (ed), Double Stitch: Black Women Write about Mothers and Daughters (pp. 42-60). Boston, MA: Beacon Press.

Consalvo, M. (2002). Cyberfeminism. In S. Jones (ed), Encyclopedia of New Media: An Essential Reference to Communication and Technology (pp. 108-9). Thousand Oaks, CA: Sage Publications.

Daniels, J. (2009). Rethinking cyberfeminism(s): Race, gender, and embodiment. Women's Studies Quarterly, 37(1), 101-124. Available at: https://www.jstor.org/stable/27655141

DiPrince, D. (2012). Motherhood, Performance, and Mommy Blogs: The Political Power of Maternal Online Rhetoric (Doctoral Thesis). Colorado State University.

Douglas, S. J. and Michaels, M. W. (2005.) The Mommy Myth: The Idealization of Motherhood and how it has Undermined Women. New York, NY: Simon and Schuster, Inc.

Duggan, M., Lenhart, A., Lampe, C. and Ellison, N.B. (2015). Parents and social media. Pew Research Center. Available at: http://www.pewinternet.org/2015/07/16/parents-and-social-media/

Ebaugh, H. R., and Mary Curry. M. (2000). Fictive kin as social capital in new immigrant communities. Sociological Perspectives, 43(2), 189-209. https:/ / doi.org/10.2307/1389793

Edison Research (n.d.). Moms and Media 2017 (editorial), Edison Research. Available at: http:/ /www.edisoresearch.com/wp-Content/uploads/2017/05/Moms-and-Media-2017-FINAL.pdf

(Accessed December 20 2018).

eMarketer (2013). Moms still make social a priority: Moms more likely to be on Facebook, Twitter than Gen X (editorial), eMarketer, 21 March. Available at: http://www.emarketer.com/Article/Moms-Still-Make-SocialPriority/1009749 (Accessed 28 November 2018).

Frankenberg, R. (1997). Displacing Whiteness: Essays in Social and Cultural Criticism. Durham, NC: Duke University Press. https:/ / doi.org/10.1215/9780822382270

Friedman, M. (2013). Mommyblogs and the Changing Face of Motherhood. Toronto, ON: University of Toronto Press.

Funderburg, L. (2012). The two friends every woman needs: Friendship is priceless — and it can also be ageless (editorial). Good Housekeeping, 25 January. Available at: https://www.goodhousekeeping.com/life/inspirationalstories/a19612/long-lasting-friendships (Accessed 18 March 2019).

Gaines, J. (2019). Life unfiltered. The Magnolia Journal, 10, 56-57.

Gibson, K. (2005). Making maladaptation palatable: Fictive kinship in adoption and religion. Available at: http://static1.1.sqspcdn.com/static/f/384896/15481602/1323212200077 (Accessed 21 December 2018).

Glenn, E. N. (1983). Split household, small producer and dual wage earner: An analysis of Chinese-American family strategies. Journal of Marriage and Family, 45(1), 35-46. https:/ / doi.org/10.2307/351293

Greenman, E. (2011). Asian American-white differences in the effect of mothering on career outcomes. Work and Occupations, 38(1), 37-67. https:// doi.org/10.1177/0730888410384935

Hays, S. (1998). The Cultural Contradictions of Motherhood. New Have, CT: Yale University Press.

Holtz, B., Smock, A. and Reyes-Gastelum, D. (2015). Connected motherhood: Social support for moms and moms-to-be on Facebook. Telemedicine and e-Health, 21(5), 415-421. https://doi.org/10.1089/tmj.2014.0118

HuffPost (2012). Babble.com's Top 100 Mom Blogs Announced (editorial). HuffPost, 13 January 2012. Available at: https://www.huffpost.com/entry/babblecoms-top-100-mom-bl_n_1147058. (Accessed 23 December 2018).

Laird, S. (2012). The rise of the mommy blogger. Mashable. Available at: http://mashable.com/video/pacers-kellykrauskopf-first-female-assistant-gm-nba (Accessed 20 December 2018).

Lopez, L. K. (2009). The radical act of mommy blogging: Redefining motherhood through the blogosphere. New Media and Society, 11(5). https:/ / doi.org/10.1177/1461444809105349

Marlow, C. (2009). How Diverse is Facebook? Available at: http://www.facebook.com/notes/facebook-datascience/how-diverse-is-facebook/205925658858 (Accessed 20 December 2018).

McCoy, T. H. (2013). Facebook moms. Newsweek. Available at: http://www.newsweek.com/facebook-moms-130 (Accessed 20 December 2018).

Morrison, A. (2010). Autobiography in real time: A genre analysis of personal mommy blogging. Cyberpsychology: Journal of Psychosocial Research on Cyberspace, 4(2). Available at: https://cyberpsychology.eu/article/view/4239. (Accessed 21 December 2018).

Nakamura, L. and Chow-White, P. (2011). Introduction-Race and digital technology: Code, the color line, and the information society, in L. Nakamura and P. Chow-White (eds), Race After the Internet (pp. 1-18). New York, NY: Routledge.

Nakayama, T. and Krizek, R. (1995). Whiteness: A strategic rhetoric. Quarterly Journal of Speech, 81(3), $291-309$. https://doi.org/10.1080/00335639509384117 
O'Reilly, A. (2011). The motherhood memoir and the new momism: Biting the hand that feeds you. In E. Podnieks and A. O'Reilly (eds), Textual Mothers/Maternal Texts: Motherhood in Contemporary Women's Literatures (pp. 203-14). Waterloo, ON: Wilfrid Laurier University Press.

Petersen, E. J. (2015). Mommy bloggers as rebels and community builders: A generic description. Journal of the Motherhood Initiative, 6(1), 9-30. Available at: https://jarm.journals.yorku.ca/index.php/jarm/article/view/ 40238/36420

Philyaw, D. (2016). Ain't I a mommy?: Why are so few motherhood memoirs penned by women of color? Bitch Media. Available at: http://bitchmedia.org/article/aint-i-a-mommy-0 (Accessed 21 December 2018).

Plantin, L. and Daneback, K. (2009). Parenthood, information and support on the internet: A literature review of research on parents and professionals online. BMC Family Practice, 10(34). https://doi.org/10.1186/1471-229610-34

Rah, S.-C. (2009). The Next Evangelicalism: Freeing the Church from Western Cultural Captivity. Downers Grove, IL: Intervarsity Press.

Schradie, J. (2012). The trend of class, race, and ethnicity in social media inequality. Information, Communication, and Society, 15(4). https://doi.org/10.1080/1369118X.2012. 665939.

Segura, D. A. and Pierce. J. L. (1993). Chicana/o family structure and gender personality: Chodorow, familism, and psychoanalytic sociology revisited. Signs, 19(1), 62-91. Available at: www.jstor.org/stable/3174745

"Teens are abandoning Facebook in dramatic numbers, study finds" (2018). The Guardian. Available at: https://www.theguardian.com/technology/2018/jun/01/facebook-teens-leaving-instagram-snapchat-studyuser-numbers (Accessed 2 May 2019).

Therriault, B. G. (2014). Moms Gone Social: A Critical Thematic Analysis of Mommy Facebooking and Its Effect on Motherhood Identities and the Good Mother Ideal (Master's Thesis). Villanova University.

Thoren, E. M., Metze, B., Buhrer, C. and Garten, L. (2013). Online support for parents of preterm infants: A qualitative and content analysis of Facebook preemie groups. Archives of Disease in Childhood - Fetal and Neonatal Edition, 98(6), F534-F538. https:// doi.org/10.1136/archdischild-2012-303572

Turkle, S. (2011). Alone Together: Why We Expect More from Technology and Less from Each Other. New York, NY: Basic Books.

Walls, S. M. (2015). Individualism in the United States: A Transformation in Political American Thought. Bloomsbury, London: Bloomsbury Academic.

Webb, L. M. and Lee, B. S. (2011). Mommy blogs: The centrality of community in the performance of online maternity, in Moravec, M. (ed), Motherhood Online (pp. 244-257). Newcastle upon Tyne: Cambridge Scholars Publishing.

Whitehead, D. (2014). The evidence of things unseen: Authenticity and fraud in the Christian mommy blogosphere. Journal of the American Academy of Religion, 83(1), 120-150. https://doi.org/10.1093/jaarel/lfu083

Citation: Gibson, C. L. (2019). Enacting Motherhood Online: How Facebook and Mommy Blogs Reinforce White Ideologies of the New Momism. Feminist Encounters: A Journal of Critical Studies in Culture and Politics, 3(1-2), 06. https://doi.org/10.20897/femenc/5912

Copyright (C) 2019 by Author/s and Licensed by Lectito BV, Netherlands. This is an open access article distributed under the Creative Commons Attribution License which permits unrestricted use, distribution, and reproduction in any medium, provided the original work is properly cited. 